\title{
BIOCHEMICAL GENETICS OF HYBRIDISATION IN EUROPEAN HOUSE MICE
}

\author{
W. GRAINGER HUNT and ROBERT K. SELANDER \\ Deportment of Zoology, University of Texos, Austin, Texos 78712, U.S.A.
}

Received 27.vii.72

\begin{abstract}
SUMmaRY
Techniques for demonstrating allozymic variation in seven enzymes (four esterases, isocitrate dehydrogenase, malic enzyme, and malate dehydrogenase) were employed to study genic variation in a narrow zone of hybridisation between allopatric semispecies of the house mouse (Mus musculus musculus and $M$. m. domesticus) on the Jutland Peninsula of Denmark. Material consisted of 2696 mice collected at 152 farms representing 44 sample areas on the peninsula and adjacent islands. The history of movements of early farming cultures with which mice were associated as commensals suggests that musculus and domesticus have been in contact and hybridising in northern Europe since 3000 B.C. The zone in Jutland and another in Germany lie in regions transitional between Atlantic and continental climates, the two parental forms meeting where they are equally well adapted to ecological conditions.

The zone in Jutland has not shifted since Ursin defined its position in 1952 on the basis of morphological characters. An analysis of genotypic proportions in populations in the zone of hybridisation failed to demonstrate assortative mating, thus supporting laboratory evidence of free interbreeding between the semispecies. Genic heterozygosity levels are " normal " on the large islands of Falster, Fyn, and Als but reduced on the small islands of Alro and Hjaelm, presumably through the founder effect or genetic drift. The zone is strongly asymmetrical north to south, with extensive introgression of domesticus alleles into musculus, but little introgression in the other direction. A marked increase in width of the zone in western Jutland is associated with a more extensive gradient of environmental factors, particularly precipitation. In the narrow eastern part of the zone, 90 per cent. of the transition in genetic character (as measured by a hybrid index) occurs over a distance of $20 \mathrm{~km}$. The extent of introgression varies markedly among loci. Linkage between the loci studied is not a major factor affecting patterns of introgression. The extreme steepness of the gradient of transition in genetic character and the occurrence of major changes in frequencies at all loci along the same line are cited as evidence that the selective values of alleles are determined in part by the internal genetic environment. The "new" genetic environment created by introgression of domesticus alleles into musculus populations apparently favours the occurrence of minor alleles at the Es-2 and Es-3 loci. The failure of the musculus and domesticus gene pools to fuse despite long-standing hybridisation argues that genetic isolation cannot be equated with reproductive isolation. Selection against introgression of the genes studied (or the chromosomal segments that they mark) is presumed to involve reduced fitness in backcross generations caused by disruption of co-adapted parental gene complexes.
\end{abstract}

\section{INTRODUCTION}

THE remarkable narrowness and apparent temporal stability of many zones of allopatric hybridisation present an intriguing problem in evolutionary genetics. Mayr (1963, p. 378) has suggested that there is in such zones " a vigorous selection against the infiltration of genes from one balanced gene complex into the other, but without the development of any isolating mechan- 
isms as a by-product of this selection". Restriction of gene flow is thus attributed to an interdependence of genes and a consequent genetic imbalance between differentiated gene pools. While Huxley (1943), Mayr (1963), Bigelow (1965) and Ford (1971) maintain that zones of allopatric hybridisation often reach stable equilibrium, with introgression balanced by selection, Wilson (1965) and Remington (1968) believe that they are generally transitory, being eliminated with the perfection of reproductive isolating mechanisms or fusion of the parental gene pools. All hypotheses invoking hybrid inferiority predict that introgression involves something more than a simple diffusion of alleles (Mayr, 1963).

The present study of variation in allele frequencies at seven gene loci through a narrow zone of hybridisation between two allopatric forms of the house mouse (Mus musculus musculus and $M$. m. domesticus) on the Jutland Peninsula of Denmark was motivated by the following questions: (1) Is introgression occurring beyond the geographic limits detected in an earlier analysis of morphology (Ursin, 1952)? (2) What environmental, historical, or other factors are important in determining the position and width of the zone? (3) Do patterns of introgression vary among loci, and is introgression symmetrical? (4) Do patterns of introgression provide evidence relevant to the current controversy regarding the selective neutrality or non-neutrality of allozymic variants?

\section{SySTEMATIC AND ECOLOGIGAL BACKGROUND}

(i) Differences between the parental forms

European house mice were assigned to two subspecies groups by Schwarz and Schwarz (1943), the spicilegus group represented by $M$. m. musculus and $M$. $m$. spicilegus, and the wagneri group including $M . m$. domesticus and $M . m$. brevirostris (fig. 1). Domesticus and musculus hybridise on the Jutland Peninsula and on a front extending from Kiel Bay on the Baltic Sea south through Germany (Zimmermann, 1949). The positions of these disjunct zones roughly correspond to those of similar zones of hybridisation involving the carrion and hooded crows (Corvus c. corone and C. c. corax), as described by Meise (1928).

Morphological and ecological differences between musculus and domesticus were discussed by Zimmermann (1949) and Ursin (1952). Musculus is a shorttailed, light-bellied mouse with a brownish yellow lateral line, whereas domesticus is long-tailed and dark-bellied, with no obvious discontinuity of colour on the sides. Domesticus is slightly larger than musculus and has more tail rings.

Schwarz and Schwarz (1943, pp. 70-72) maintained that domesticus is a specialised commensal, while musculus has not progressed beyond " a primitive stage of commensalism ". But Ursin's (1952) and our field work in Denmark indicates that musculus is fully as successful as domesticus in exploiting farm buildings and other man-made " habitats". Zimmermann (1949) reported that musculus is more resistant to cold and has a greater tendency to winter outdoors, but populations of either form rarely overwinter in fields in Denmark (Ursin, 1952). The long tail of domesticus was regarded by Schwarz and Schwarz as an adaptation for commensalism, but Zimmermann questioned this interpretation by demonstrating that variation in tail length in Europe follows Allen's rule. 
In a study of the behaviour of laboratory-raised individuals of both forms and their $F_{1}$ hybrids, Brubaker (1970) found that domesticus showed greater wheel-running, swimming and "open field" activity, while musculus had a greater tendency to hoard. We have noted that wild-caught domesticus struggle vigorously and bite when handled, whereas musculus are relatively docile and infrequently bite. Musculus is also more active than domesticus in the daytime.

Musculus and domesticus differ more in appearance and behaviour than the average run of subspecies designated by taxonomists, and they are quite distinct genetically. From an analysis of allozymic variation in Jutland

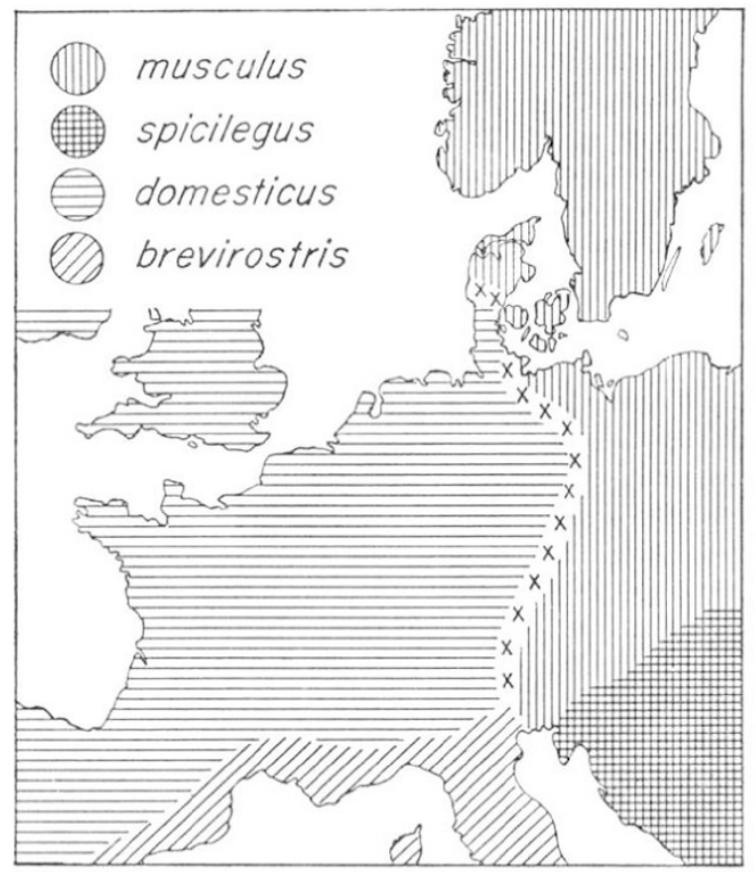

FIG. 1.-European distribution of four subspecies of Mus musculus. Zones of allopatric hybridisation between musculus and domesticus are indicated by crosses.

populations of musculus and domesticus, Selander, Hunt and Yang (1969) derived a coefficient of genetic similarty of 0.79 , a value close to those obtained for sibling species of the rodents Sigmodon and Peromyscus (Selander and Johnson, 1973). Considering the relatively strong differentiation of musculus and domesticus and, more importantly, the apparent isolation of their gene pools despite hybridisation (see Discussion), it is realistic to consider them semispecies rather than subspecies.

\section{(ii) Establishment of the zone of hybridisation}

Zimmermann (1949) suggested that musculus was derived from spicilegus and reached the Baltic Sea area during the post-glacial optimum, when several other dry-land vertebrates now represented in northern Europe by relic populations ranged north to the Baltic Sea. (House mice have been reported from an early post-glacial forest fauna in central Germany by 
Brunner, 1941.) Following its establishment in northern Europe, musculus is presumed to have changed from an entirely aboriginal to a partially commensal form and subsequently to have accompanied the spread of grainfarming into north-central France, establishing itself over much of northern Europe by 4200 B.c.

Domesticus is believed to have reached Europe later than musculus, arriving as a commensal associated with the neolithic grain culture that spread from North Africa into Spain and southern France (Zimmermann, 1949). By 3000 B.C. the long-isolated farming traditions of the western Mediterranean and northern and eastern Europe made contact, and at this time it is likely that domesticus came to occupy Britain, northern France, and western Germany. The probable position of the zone of contact of these cultures, as described by Waterbolk (1968), lies several hundred miles west of the present boundary between domesticus and musculus. Because the European distribution of musculus corresponds to the drier " continental " climate, and that of domesticus to the wetter "Atlantic " climate, the shift in the zone of contact may have been caused by an eastward movement of the climatic boundary since 3000 B.c. Alternatively, domesticus simply may have replaced populations of musculus that earlier had occupied the eastern margin of the Atlantic climatic region. In any event, it is likely that interbreeding occurred when the two forms first met and that a zone of hybridisation has existed in some form in central-northern Europe for several thousand years.

The present disjunction of the northern Jutland and German populations of musculus presumably was established as the zone of contact moved eastward, thus permitting domesticus to occupy the southern Jutland Peninsula. This invasion did not displace musculus from the larger islands in the western Baltic Sea, including Als and Fyn.

\section{(iii) The environment of Futland}

The Jutland Peninsula is $435 \mathrm{~km}$. long and varies in width from $50 \mathrm{~km}$. at the German border to $178 \mathrm{~km}$. in the central region. The topography is principally the result of Quaternary glaciation, and particularly the last glacial period, when ice sheets covered the northern and eastern parts (Davies, 1944). Ice emanating from Scandinavia retreated earlier and more rapidly than that which had spread westward from the Baltic. Consequently, eastern Jutland has a greater and more varied relief than northern Jutland because of the longer period available for the accumulation of morainic deposits. In northern Jutland the soil is mainly sandy loam of relatively low fertility, and the terrain is bare and windswept. The landscape of eastern Jutland is characterised by numerous valleys and rounded hills (up to $172 \mathrm{~m}$. in elevation), and soils are mainly clay loam and sandy loam. Because glacial drainage flowed westward, western Jutland is a flat, sandy outwash plain with scattered low sandhills formed in the second glacial period. In geology and landscape, the Danish islands are similar to eastern Jutland.

Because of the small size and gentle relief of Jutland, there are no large rivers. Many small lakes occur on the peninsula, and there is a large estuary, the Ringkøbing Fjord, in central-eastern Jutland. The northern and central regions are separated by the Limfjord, a waterway extending from the North Sea to the Baltic Sea.

The climate of Jutland and adjacent islands is fairly uniform. However, mean yearly precipitation decreases from south to north, and the transition 
occurs much more gradually in western than in eastern Jutland (fig. 2). The lowest temperatures occur inland in the central and northern half of the peninsula, but the actual range of geographic variation in temperature is very small.

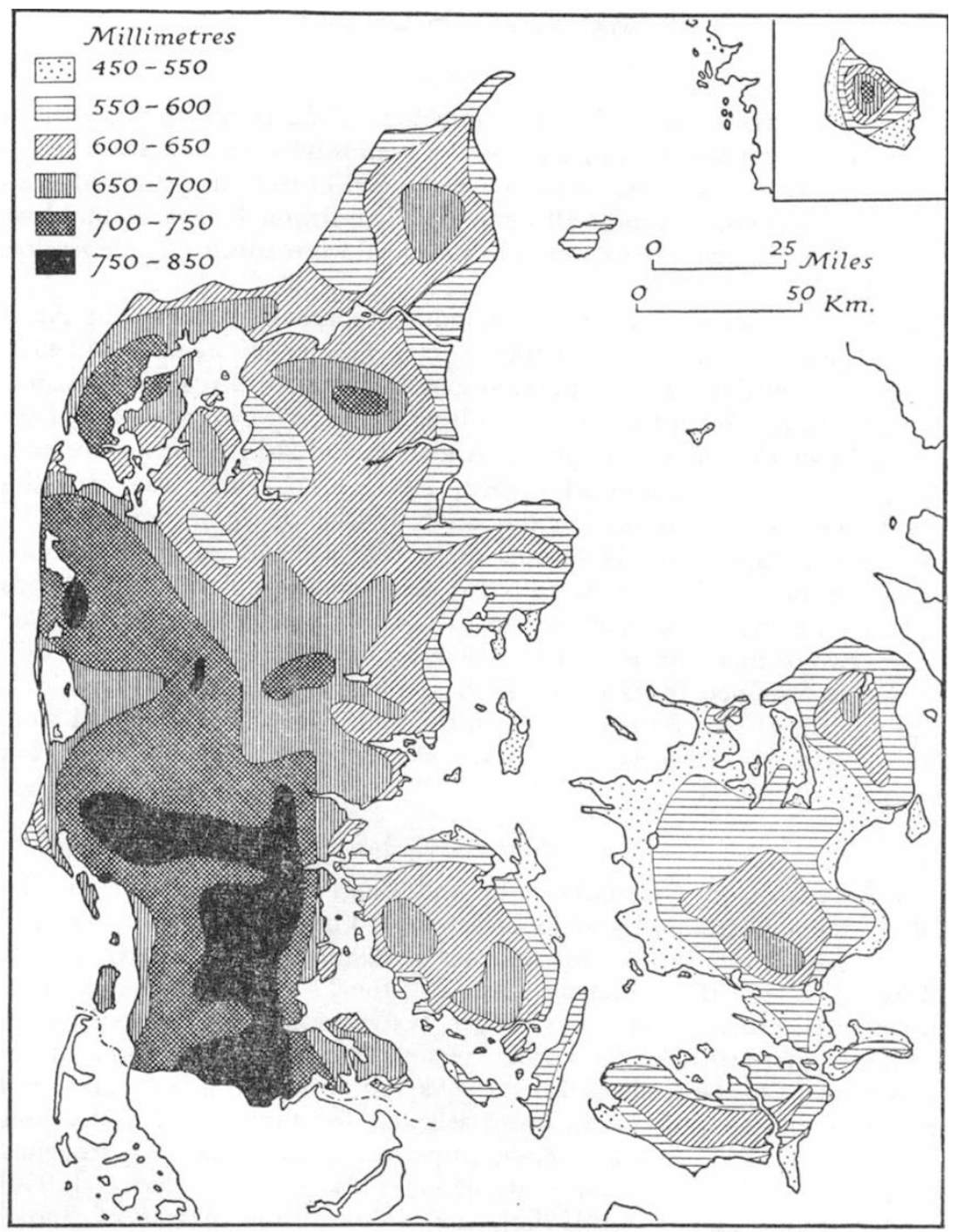

FIG. 2.-Total yearly precipitation in Denmark. From Davies (1944) after Danske Meteorol. Inst. (1933, plate 40).

The distribution of native vegetation and agricultural crops (predominantly cereals) corresponds fairly well to that of soil types. Eastern Jutland and the islands have been under cultivation for centuries, with forest largely confined to the higher land and steeper slopes. Before 1800 large regions of sandy soil in western and central Jutland were covered by a native heath. Although farming has increased in the west and north in the last 100 years, 
the density of towns and farms has remained much lower in these regions than in the east. Agriculture is now very uniform throughout Denmark; approximately four-fifths of the land area is agricultural, and of this more than 80 per cent. is arable (Davies, 1944).

\section{Materials and methods}

\section{(i) Samples}

A total of 2696 house mice was collected at 152 farms on the Jutland Peninsula and on five islands east of the peninsula from August 1968 to February 1969 (fig. 3). Because attempts to collect mice in grainfields were generally unsuccessful, almost all mice were live-trapped in farm buildings or captured when grain ricks were threshed. All were adults or independent subadults.

Studies of allozymic variation in house mouse populations in North America have demonstrated marked heterogeneity in allele frequencies among barns on the same farm and among farms in local regions (Selander and Yang, 1969; Selander, 1970), resulting from the polygynous, tribal and territorial social system of the species (Anderson and Hill, 1965; Reimer and Petras, 1967; DeFries and McGlearn, 1972). To reduce the confusing effect of local differentiation in our analysis of geographic variation, the farms were grouped into 44 sample areas (fig. 3), and estimates of allele frequencies for sample areas were based on pooled samples from all farms. With three exceptions (insular sample areas 42, 43 and 44), each sample area includes two or more farms. (A complete list of farms and numbers of mice collected is provided by Hunt [1970].) Farms were coded alphabetically within sample areas. Sample areas on the mainland were numbered along three south-north transects as follows: eastern, 1-16; central, 17-30; and western, 31-39 (fig. 3).

\section{(ii) Allozymic analysis}

In an earlier study (Selander, Hunt and Yang, 1969), allozymic variation in 36 proteins controlled by 41 loci was assessed in two samples of domesticus from southern Jutland and four samples of musculus from northern Jutland and islands east of the peninsula. At 13 of the 17 variable loci there were marked differences in allele frequencies between the semispecies; and at several loci alternate alleles were fixed or nearly so in northern and southern populations. On the basis of this survey seven polymorphic enzymes (each encoded by a separate locus) were selected for detailed analysis: four esterases ( $E_{s-1,} E_{s-2}, E_{s-3}$ and $E_{s-5}$ ), supernatant isocitrate dehydrogenase (Idh-1), supernatant malic enzyme (Me-1) (Mdh-1 of Henderson [1966], Selander, Hunt and Yang [1969], and others; and Mod-1 of Shows, Chapman and Ruddle [1970]), and mitochondrial malate dehydrogenase (Mdh-2) (Mor-1 of Shows, Chapman and Ruddle [1970]).

Techniques of tissue preparation, electrophoresis and protein staining are described by Selander and Yang (1969). Because of the expense of staining for IDH, ME and MDH, the numbers of mice typed for these enzymes were reduced for most areas represented by samples exceeding 30 . Mean sample sizes per area were 60 for esterases and 28 for other enzymes.

The distribution of allozymic variants in the house mouse has been studied in natural populations in North America (Petras et al., 1969; Ruddle et al., 


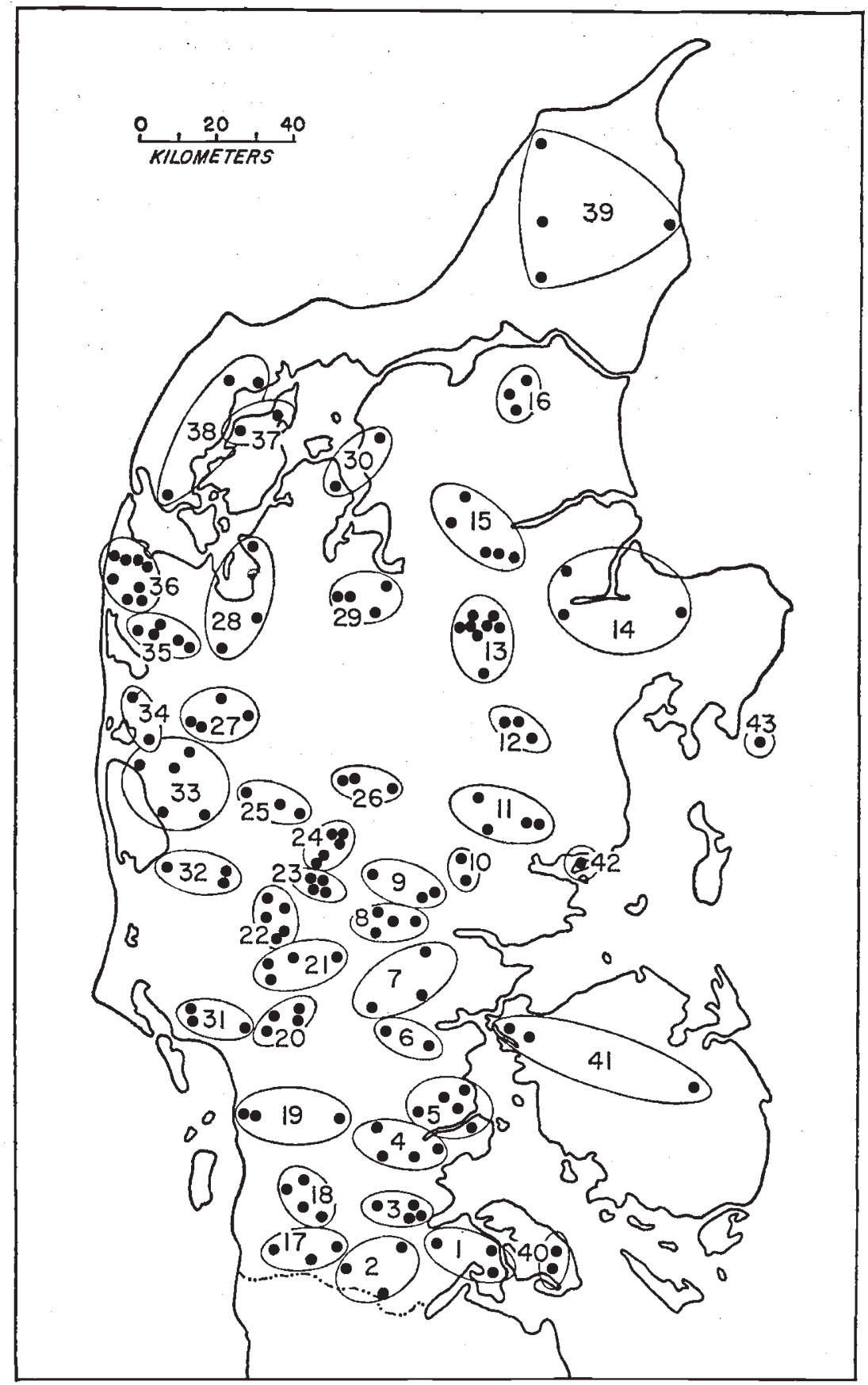

Fig. 3. - Sample localities for specimens of Mus musculus. Samples from individual farms (dots) are grouped into numbered sample areas, as indicated. The insular populations are as follows: 40, Als; 41, Fyn; 42, Alrø; and 43, Hjaelm. Falster Island (44) lies east of the area shown. 
1969; Selander and Yang, 1969; Selander, Yang and Hunt, 1969), the Hawaiian Islands (Wheeler and Selander, 1972), parts of Britain (Berry and Murphy, 1970), and Jutland (Selander, Hunt and Yang, 1969). The distribution of alleles in inbred strains was summarised by Roderick et al. (1971) and Taylor (1972). The literature on breeding experiments demonstrating the generally codominant inheritance of allozymic variants is cited in these papers and in those mentioned in the following paragraph. A genetic analysis of variants in Jutland populations was presented by Wheeler (1972).

The linkage relationships of the loci considered are as follows: E.s-1, $E s-2$ and $E_{s-5}$ are in linkage group XVIII (Petras and Biddle, 1967; Popp, 1967; Ruddle, Shows and Roderick, 1969; Wheeler and Selander, 1972). Average recombination frequencies from several studies are 0.100 for $E s-1$ and $E s-2,0.080$ for $E s-1$ and $E s-5$, and 0.009 for $E s-2$ and $E s-5$, suggesting the linear arrangement $E s-1, E s-5, E s-2$, with only $E_{s-5}$ and $E s-2$ tightly linked. Es-3 is in group VII (Roderick, Hutton and Ruddle, 1970); Idh-1 is in group XIII (Hutton and Roderick, 1970; Chapman, Ruddle and Roderick, 1971); and $\mathrm{Me-1}$ is in group II (Shows, Chapman and Ruddle, 1970). The linkage group for $M d h-2$ has not been determined.

\section{Results}

\section{(i) Polymorphic variation}

Alleles are of two types, "major" alleles in moderate or high frequency in one or both semispecies and " minor" alleles in low frequencies with generally localised distribution. Geographic variation in frequencies of major alleles is shown in figs. 4 to 7. (Genotypic and allelic frequencies for all samples are presented by Hunt [1970].)

\section{(a) Esterase-1}

Populations of musculus in northern Jutland are monomorphic for the $E s-1^{a}$ allele, and those of domesticus near the German border are monomorphic for $E s-1^{b}$ (fig. 4). Introgression is more or less symmetrical north to south but is more extensive in western than in eastern Jutland. The distance between the 0.10 and 0.90 isofrequency lines for the $E s-1^{a}$ allele is $100 \mathrm{~km}$. in the west but only $30 \mathrm{~km}$. in the east. On Als Island (sample area 40), Es-1a has a frequency of 0.04 , presumably reflecting introgression from the adjacent mainland, but other insular populations (Fyn, 41; Alrø, 42; Hjaelm, 43) are monomorphic for $E s-1^{b}$.

A minor null allele, $E s-1^{c}$, occurs at a frequency of 0.18 in sample area 39 in northern Jutland.

\section{(b) Esterase-2}

Six alleles are represented, two of which, $E s-2^{b}$ and $E s-2^{c}$, are major. Shown in fig. 4 are the adjusted (relative) frequencies of the major alleles, calculated by eliminating minor alleles. $E s-2^{b}$ and $E s-2^{c}$ are essentially fixed in domesticus and musculus, respectively. Introgression is asymmetrical north to south: $E s-2^{b}$ penetrates to the Limfjord, but there is little introgression of $E s-2^{c}$ into southern populations. Again, the zone of transition in allele frequencies is broader in the west than in the east; distances between the 0.10 and 0.90 isofrequency lines for $E s-2^{c}$ are 120 and $45 \mathrm{~km}$. respectively. 
Populations on Als and Fyn islands are slightly introgressed from the mainland.

$E s-2^{a}$, a null allele, was detected in homozygous state in five sample areas in north-central Jutland. This allele may also occur in low frequency elsewhere on the peninsula, but, because it is undetectable in heterozygous condition, we could not determine its frequency directly. Maximum likelihood methods of estimating frequencies of null alleles from heterozygote

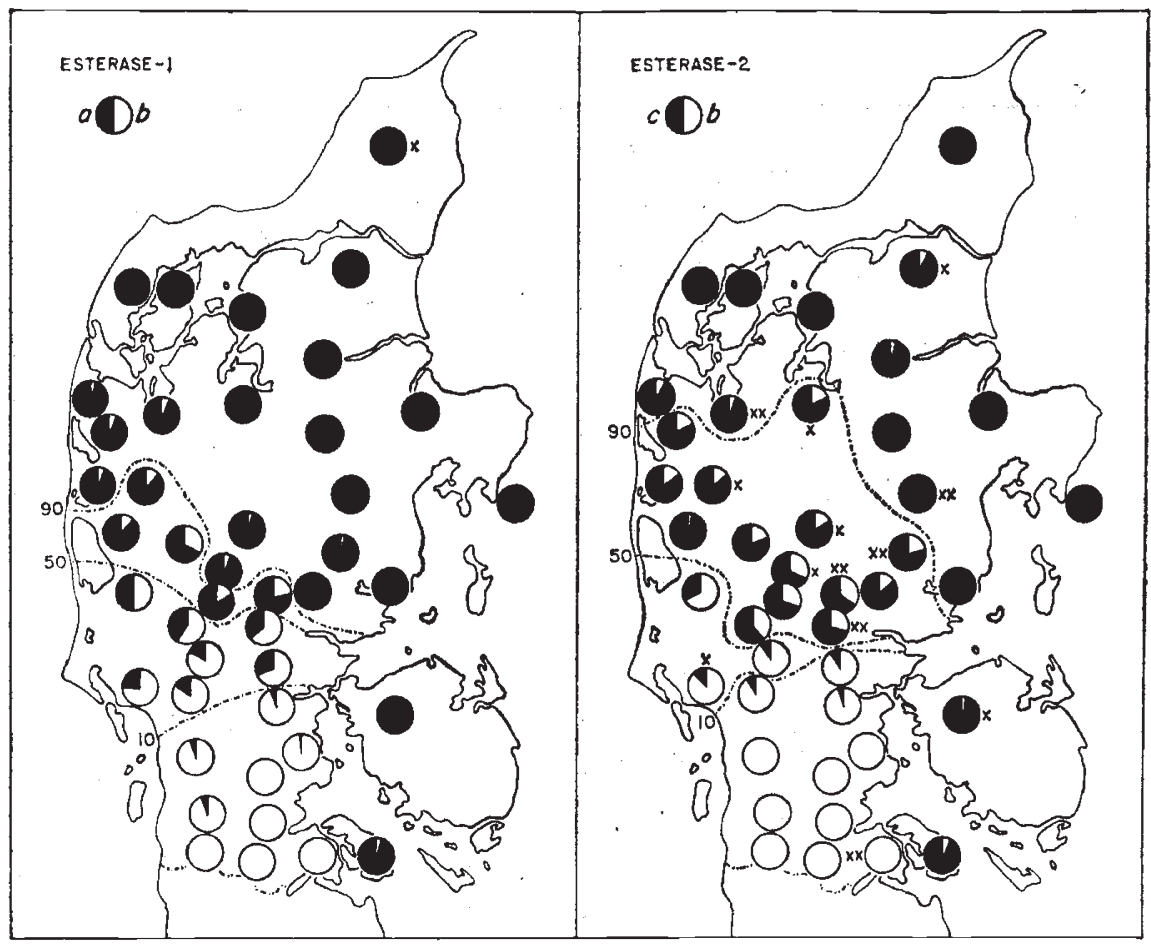

Fic. 4.-Geographic variation in frequency of major alleles at the Es-1 and Es-2 loci. Isofrequency lines for the $E s-1^{a}$ and $E s-2^{c}$ alleles are indicated. The occurrence of minor alleles is indicated by an $X$.

deficiencies in samples were considered inappropriate because of complications of the Wahlund effect (Selander, Yang and Hunt, 1969). Es-2e occurs in low frequency in eight sample areas, $E s-2^{f}$ in five, and $E s-2^{g}$ in two.

\section{(c) Esterase-3}

Populations in 43 of the 44 areas sampled are polymorphic for $E_{s-3^{b}}$ and $E s-3^{c}$ (fig. 5). There is no conspicuous geographic variation in allele frequencies, but $E s-3^{b}$ occurs in slightly higher frequency, on the average, in the southern and western parts of the peninsula than in the north-eastern region occupied by relatively "pure" populations of musculus. This pattern is consistent with evidence from other loci of a more extensive introgression in the west than in the east. The frequency of $E s-3^{b}$ is surprisingly low (0.09) in sample area 1 , being only slightly higher than that $(0.06)$ on the adjacent Als Island. 
A null allele, $E s-3^{e}$, was recorded in three sample areas, and $E s-3^{f}$ was found in four areas.

\section{(d) Esterase-5}

Phenotypic variation in esterase- 5 involves the presence or absence of a band of enzymatic activity. Presence results from a dominant allele, $E s-5^{b}$, while absence reflects homozygosity of the null $E s-5^{a}$ allele (Petras and Biddle, 1967). $E s-5^{a}$ is fixed or nearly so in musculus, but domesticus is polymorphic, with $E s-5^{b}$ in frequencies of approximately 0.20 to 0.30 . In fig. 5, variation at the $E s-5$ locus is expressed in terms of the frequency of the homozygous

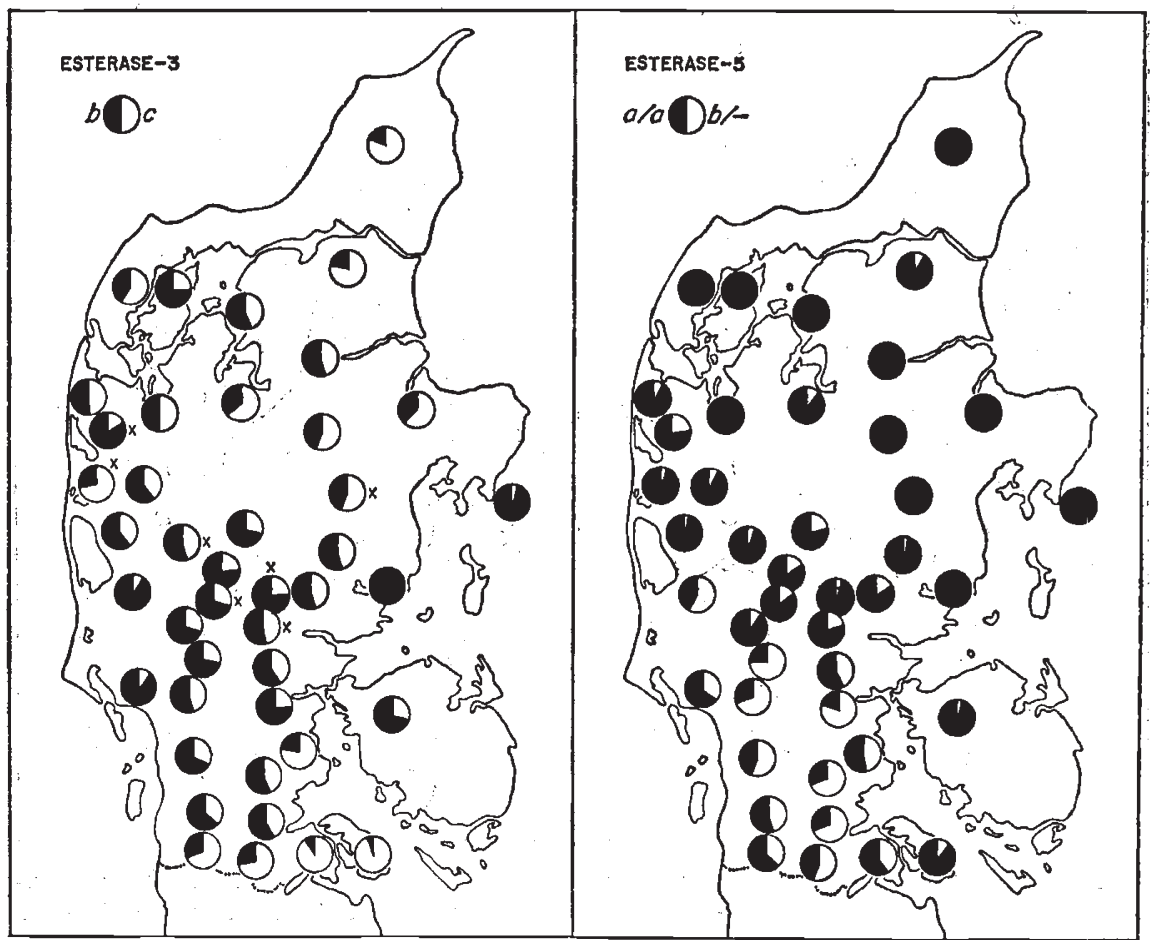

Frg. 5.-Geographic variation in frequency of major alleles at the $E s-3$ locus and of genotypes at the Es-5 locus. The occurrence of minor $E s-3$ alleles is indicated by an X.

$E s-5^{a}$ phenotype. The introgressive pattern at the $E s-5$ locus is similar to that at $E s-2$. $E s-5^{b}$ penetrates far into musculus, particularly in the west, but the relative uniformity of frequencies in southern populations indicates that little introgression is occurring from musculus to domesticus. Populations on Als and Fyn islands apparently are slightly introgressed from the mainland.

\section{(e) Isocitrate dehydrogenase-1}

$I d h-1^{a}$ and $I d h-I^{b}$ are, with few exceptions, alternately fixed in populations of domesticus and musculus, respectively (fig. 6). Introgression is symmetrical north to south, as in the case of $E s-1$, but asymmetrical east to west. If the presence of $I d h-1^{b}$ in southern Jutland is in fact the result of introgression, this is the only locus at which a musculus allele has penetrated all the way to the German border. Introgression of $I d h-1^{a}$ from domesticus also appears 
unusually extensive, with this allele being represented in areas beyond the Limfjord (38 and 39). The presence of $I d h-I^{b}$ at a frequency of 0.12 in sample area 1 suggests gene flow from Als Island, where populations appear also to be introgressed from the mainland. Idh- $1^{b}$ is fixed in other insular populations.

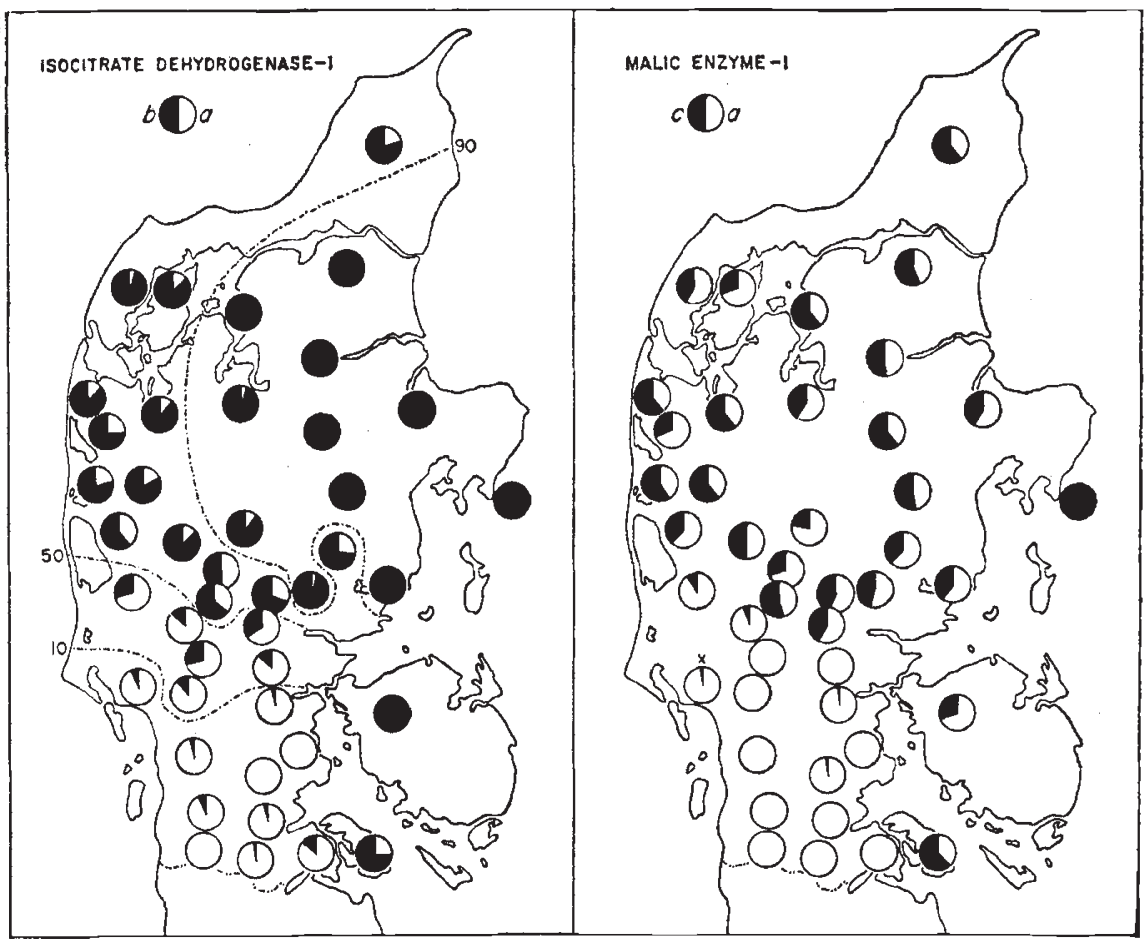

Fig. 6.-Geographic variation in frequency of major alleles at the $I d h-I$ and $M e-I$ loci. The occurrence of the minor allele $M e-1^{d}$ is indicated by an X.

(f) Malic enzyme-1

Domesticus is monomorphic for $M e-1^{a}$, while musculus is polymorphic for $M e-1^{a}$ and $M e-1^{c}$ (fig. 6). The transition in central Jutland is very sharp, and there is little evidence of introgression of $M e-1^{a}$ into northern populations, even on the western side of the peninsula. Some penetration of $M e-1^{c}$ into southern populations is apparent, however.

A third allele, $M e-1^{d}$, was found in sample area 31 in south-western Jutland.

\section{(g) Malate dehydrogenase-2}

The pattern of variation at $M d h-2$ is similar to that at $M e-1$ in that domesticus is monomorphic $\left(M d h-2^{b}\right)$ and musculus is polymorphic for two alleles $\left(M d h-2^{b}\right.$ and $\left.M d h-2^{c}\right)$. Introgression from musculus into domesticus is not apparent, but the relatively high frequency of $M d h-2^{b}$ in north-western Jutland presumably reflects extensive introgression from the south (fig. 7).

A third allele, $M d h-2^{a}$, was found in two sample areas in northern Jutland. 


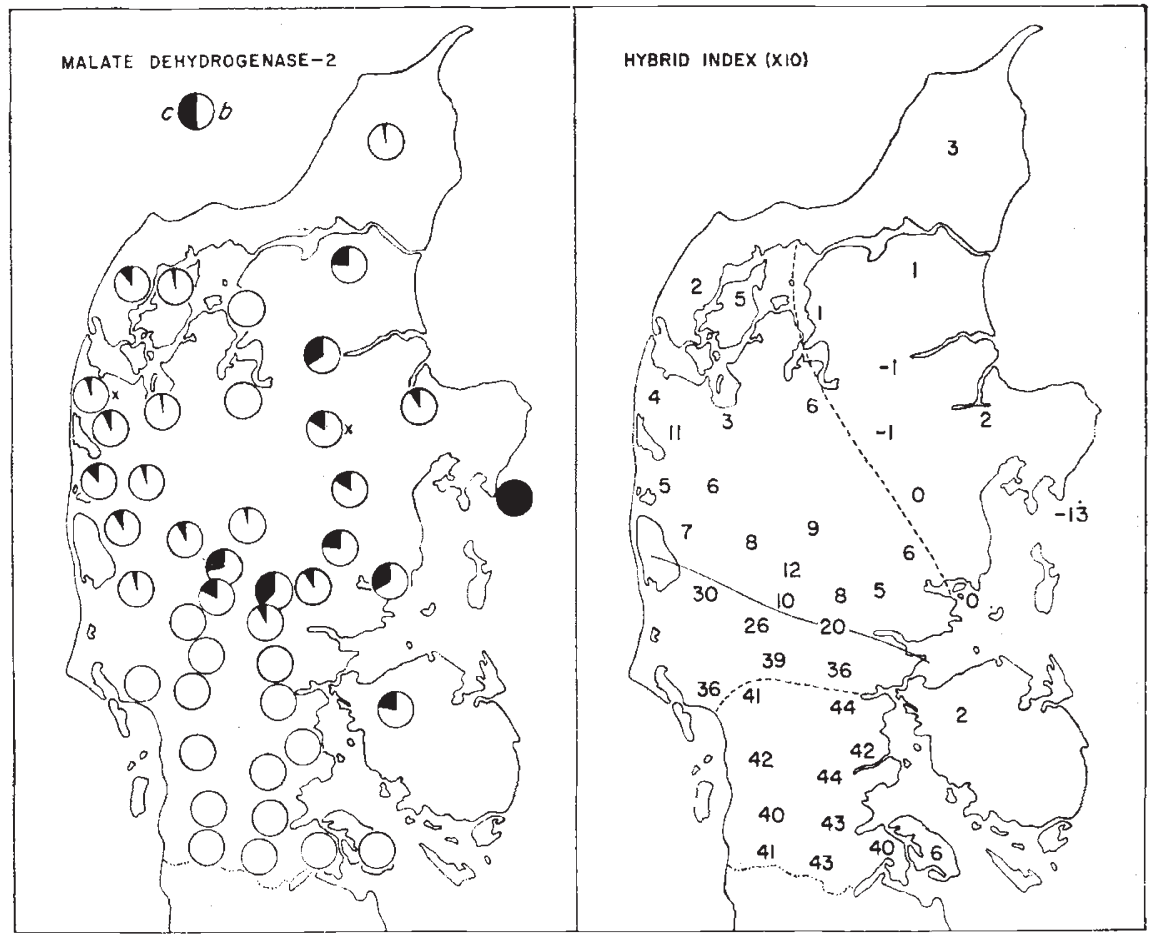

FIG. 7.-Left: Geographic variation in frequency of major alleles at the $M d h-2$ locus. The occurrence of the minor allele $M d h-2^{a}$ is indicated by an X. Right: Geographic variation in hybrid index score $(I \times 10)$ based on six polymorphic loci. Dashed lines indicate limits of introgression, as reflected by $I$, and the continuous line indicates the centre of the zone of hybridisation.

\section{(ii) Hybrid index}

To measure overall genetic character, a hybrid index score $(I)$ for each sample area was computed as follows:

$$
\begin{aligned}
I=f_{E \&-1 b}+f_{E 8-2 b}+f_{I d h-1 a}+\left(1-f_{E \&-5 a / E z-5 a}\right)+\left(f_{M e-1 a}-0 \cdot 487\right) \\
+\left(f_{M d h-2 b}-0.818\right) .
\end{aligned}
$$

Frequencies of alleles are adjusted ones, and $f_{E \xi-5 a / E s-5 a}$ is the frequency of the null phenotype. The value 0.487 is the mean frequency of $M e-1^{a}$ in sample areas 12 through 15, representing minimally introgressed musculus, and 0.818 is the mean frequency of the $M d h-2^{b}$ allele in these areas. The index is designed to yield highest scores $(\sim 4.2)$ for "pure "populations of domesticus (2, 3, 17 and 18) and lowest scores $(\sim 0 \cdot 0)$ for those of musculus (12 to 15$)$. Es-3 was excluded because it provides little information on introgression.

The centre of the zone of hybridisation can be represented as the $2 \cdot 1$ isofrequency line, which lies between sample areas 7 and 8 in eastern Jutland, between 22 and 23 in the centre of the peninsula, and between 32 and 33 in the west (fig. 7). North-south and east-west introgressive asymmetries are readily apparent. 
To illustrate the transition from musculus to domesticus in greater resolution, we have in fig. 8 shown hybrid index values for individual farms in central Jutland for which relatively large samples are available. Most of the transition in the eastern region occurs over a distance of less than $20 \mathrm{~km}$. Interfarm heterogeneity within sample areas also is demonstrated in fig. 8.

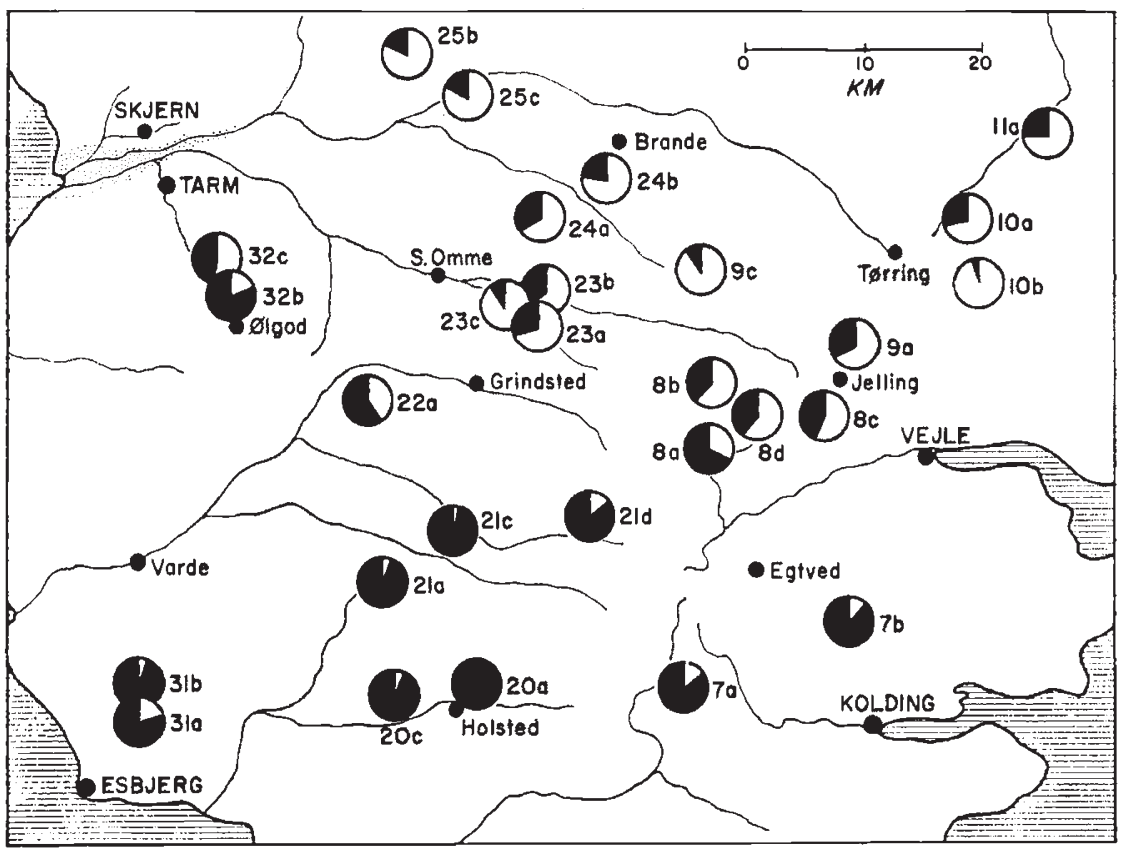

Fro. 8. - Interfarm variation in overall genic character at six polymorphic loci in central Jutland. Each circle represents a farm. Black areas of circles are proportional to hybrid index values, expressed as percentages of $4 \cdot 2$, the average value for samples of "pure" domesticus. Marshland between Skjern and Tarm is indicated by stippling.

\section{(iii) Degree of interbreeding}

Evidence from the field and laboratory indicates that, if interbreeding between musculus and domesticus is not entirely free, at least there is no strong tendency for assortative mating. In samples from individual farms within the zone we have not detected evidence of selective mating, the proportions of genotypes in samples from individual farms being similar to those expected in panmictic populations (data in Hunt, 1970; see also table 2).

\section{Discussion}

\section{(i) Comparison with Ursin's earlier analysis}

The centre of the zone of hybridisation defined by Ursin's (1952) study of pelage colour and skin and skeletal dimensions extended from Fredericia (near Vejle) west through Grindsted to a point between Tarm and Skjern (see localities in fig. 8). That this is also the line defined by our analysis indicates that the centre has not shifted in the 20 years since Ursin's study.

Because the tail and hindfoot were slightly shorter in musculus populations north of the Limfjord than in those south of this channel, Ursin concluded that " weak gene-flow" from domesticus could be traced north to the Limfjord, 
an inference confirmed by our demonstration of introgression in the western part of the peninsula at least as far north as Mors Island (37) in the Limfjord (fig. 7). (In the case of $I d h-1$, introgression may extend to the northern tip of the peninsula.) Ursin's data suggested a north-south asymmetry, for he could not detect with certainty introgressive effects south of the Vejle-GrindstedSkjern line. We have shown that introgression is relatively limited south of the centre of the zone (fig. 7), especially in the east, although at $E s-1$ and $I d h-1$ it can be traced almost to the German border. The east-west asymmetry apparent from our study was also suggested by Ursin's data.

Populations on islands east of the Jutland Peninsula were assigned to musculus by Ursin, with the comment that they are similar to those north of the Limfjord. Our sample from Falster, a large island $120 \mathrm{~km}$. east of the peninsula, is " pure" musculus $(I=-0.53)$. Similarly, the Fyn population is not appreciably introgressed $(I=0.22)$, but the Als population $(I=0.55)$ shows slight introgression at most loci. The clearest indication of gene flow from Als to the adjacent mainland is provided by the relatively high frequency of $I d h-1^{b}$ in sample area 1 (fig. 6).

Because the narrow channels separating Fyn and Als from the mainland are bridged by highways along which there is a heavy traffic of agricultural products in which mice could be carried, the severe restriction of gene flow is surprising. It may be significant that in climate and soil type Fyn and Als resemble the north-eastern area of Jutland occupied by musculus rather than the adjacent mainland inhabited by domesticus (see fig. 2).

Genic heterozygosity levels are " normal " on the large islands of Falster, Fyn, and Als. On the small island of Alrø, Es-3, a locus polymorphic in all mainland populations, is monomorphic (fig. 5). Hjaelm Island is occupied by a small population presumably founded by a few individuals and dependent for its existence on the lighthouse station located there. $M e-1$ and $M d h-2$, which are polymorphic in musculus on the adjacent mainland, have been fixed on Hjaelm (figs. 6 and 7), presumably through the founder effect or genetic drift, but $E s-3$ remains weakly polymorphic (fig. 5).

\section{(a) Position}

\section{(ii) Position and width of the zone}

The question of whether hybridisation between musculus and domesticus is stable or transient pertains to both the location and width of the zone. As noted earlier, circumstantial evidence of an eastward shift in the zone from its original position is provided by its present disjunction in Jutland and Germany. The fact that these zones lie in regions of transition between Atlantic and continental climates suggests that climatic factors influence their positions (see also beyond). Since musculus and domesticus are almost entirely commensal in habit, their distributions and densities also undoubtedly have been influenced by historical changes in agricultural practices and the distribution of human populations. If, as suggested by Ursin (1952), the two forms meet where they are equally well adapted to ecological conditions, temporal variation in these conditions will preclude long-term stability of position of the zones.

How long musculus and domesticus have been in contact along their present front in central Jutland is unknown, but the western part of the zone cannot have existed in its present form prior to the mid-nineteenth century. Through prehistoric and early Christian times, much of Jutland was covered with oak 
and beech forest (Davies, 1944). This habitat and the scattered farming communities would have supported populations of Mus, but the nonforested sandy outwash plains and marshy areas in the west probably would have been only sparsely and locally inhabited. In eastern Jutland the zone could have existed in much its present form and position for centuries, following the extensive destruction of forests in medieval times, but only tenuous avenues of contact between musculus and domesticus could have existed in the west prior to the 1850s, when a major programme of reclamation of heathlands and improvement of soil conditions was initiated, permitting an extensive development of agriculture on the sandhill islands and plains. Similarly, prior to the programme of reclamation of marshlands initiated in south-western Jutland in the mid-nineteenth century, human settlement was concentrated on scattered islands of drier land rising from meadows and bogs. The extensive peat bogs of northern Jutland and marshlands adjacent to the Limfjord, now partly reclaimed, also may have affected the distribution of musculus in earlier times.

Ursin emphasised the abruptness of the transition between musculus and domesticus, noting (1952, p. 235) that " populations with conspicuous hybrid characters apparently are met with only within an area the breadth of which is about $50 \mathrm{~km}$. . . . Only within a zone of at most a few kilometres are the hybrid characters so pronounced that it is doubtful to what subspecies the population is most nearly related." The transition in overall genetic character in central Jutland is shown in fig. 9, in which hybrid index scores for sample areas along three transects are plotted against distance from south to north on the peninsula. Along the Vejle transect in the east (sample areas 1 to 16), "pure" musculus and "pure" domesticus populations are found within $80 \mathrm{~km}$. of one another, and 90 per cent. of the transition in hybrid index occurs over a distance of $20 \mathrm{~km}$. But along the Skjern transect in the west introgression is evident for a distance of at least $50 \mathrm{~km}$. south of the centre of the zone and may extend northward up the coast beyond the Limfjord, a distance of more than $200 \mathrm{~km}$.

Minor variation among loci in position of the mid-line of the zone probably is unimportant, considering the large part played by stochastic processes in determining allele frequencies at individual farms. Recall that we are dealing with disjunct, semi-isolated populations on farms, and that marked genetic heterogeneity exists among farms within small regions, largely as a result of founder effects (Selander, 1970). Founder effects and sampling error are probably also responsible for the few obvious " reversals" in the gradient of character transition detected in our study. As shown in fig. 7, sample area 23 has a lower hybrid index than area 24, owing to an unexpectedly high frequency of the musculus alleles $I d h-I^{b}$ and $M e-1^{c}$ (fig. 6). (Allele frequencies at other loci in area 23 are "properly" intermediate between those of areas 22 and 24.) Another reversal occurs in the west, where the hybrid index for sample area 35 is unexpectedly high $(1 \cdot 1)$ as a consequence of variation at Es-2, Es-5, Idh-1 and Me-1.

The centre of the zone does not correspond to any sharp natural or manmade ecological discontinuity or to any obvious barrier to dispersal; and at least in the central and western parts of the peninsula it does not correspond to a steepening of gradients of environmental factors. The centre in the east lies near Vejle, where total yearly precipitation decreases northward from 800 to $625 \mathrm{~mm}$. over a distance of $30 \mathrm{~km}$. (figs. 2 and 9). Elevation is also 


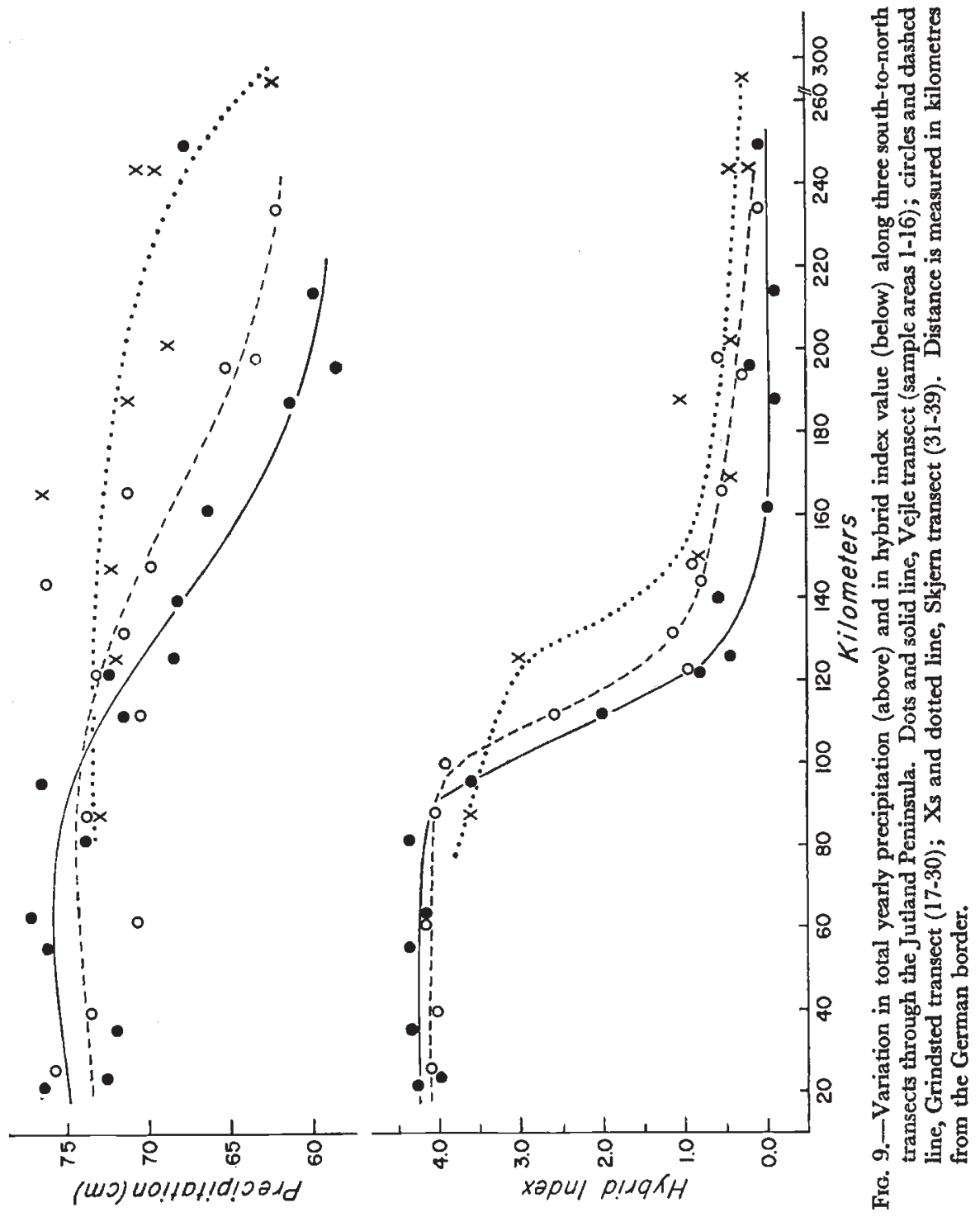


increasing in this region, so that areas above $100 \mathrm{~m}$. occur just north of the mid-line. In the west, however, environmental correlates with the centre of the zone are less apparent. If precipitation alone were determining the position of the zone, we might expect the mid-line to lie near the south-western border of the Limfjord. Rather, it falls between Skjern and Tarm, where there is no abrupt change in precipitation, elevation, or soil type.

As shown in fig. 8, it is not apparent that the streams in Jutland affect gene flow in the central and eastern parts of the peninsula. For example, the characters of populations north (23b) and south (23a) of the Grindsted River are similar, as previously noted by Ursin (1952). However, the extensive marshes between Skjern and Tarm, where the Skjern and Grindsted rivers flow into the Ringkøbing Fjord, may impede dispersal. Ursin identified musculus at Skjern and domesticus at Tarm, only about $5 \mathrm{~km}$. distant. Our material from near Tarm is strongly domesticus-like in character $(I=3.0)$, while that from just north of Skjern is strongly musculus-like $(I=0 \cdot 7)$. However, a similar change in $I$ occurs in an equally short distance $(\sim 20 \mathrm{~km}$.) in the eastern part of the zone, where there are no obvious barriers to migration. In the east, the partial barrier to dispersal formed by the Vejle Fjord and the forested hills between Vejle and Jelling does not seem sufficient to account for the abruptness of the transition. Surprisingly, patterns of variation do not appear to be influenced by the Limfjord, which at least under more primitive conditions would have been a major barrier to dispersal of mice.

\section{(b) Width}

If the width of the hybrid zone in Jutland is not stable, the rate of expansion or contraction must be extremely low, for it is likely that musculus and domesticus have been hybridising in cental Europe for thousands of years. For Mus at least, we cannot agree with Remington's (1968, p. 375) suggestion that "the amount of natural hybridizing is commonly more a measure of recency of first sympatry than a measure of the amount of genetic dissimilarity ...". At the same time, we cannot judge whether the width of the zone is slowly changing. Bigelow's (1965) suggestion that in transient zones trends toward "incorporation" should be detectable within a few generations may be an overly optimistic assessment of such situations. Computer simulations of zones of secondary contact or of clines of variation maintained by the opposing forces of selection and gene flow (Jain and Bradshaw, 1966; Crosby, 1969; Cook, 1972) emphasise the slowness with which equilibrium conditions are attained. With weak selection against introgressant alleles and a low migration rate, several thousand generations may be required to reach equilibrium at a locus initially fixed for different alleles in the parental forms. As noted by Fincham (1972) in regard to balanced polymorphisms, " most land environments may not be sufficiently stable for long enough periods for true equilibria ever to be attained ". In any event, the question of absolute or relative stability is in the present case of little consequence in attempting to understand factors determining the extent of introgression at different loci.

A notable feature of the zone is that introgression at most loci is more extensive into musculus than into domesticus. This type of asymmetry is a common feature of allopatric hybrid zones (Short, 1965; Yang and Selander, 1968). In the case of Mus it could reflect one or a combination of conditions, 
including (1) greater interfarm migration in musculus than in domesticus, or a net northward dispersal; and (2) lesser intensity of selection against introgressant alleles in musculus populations than in those of domesticus.

Variation in width is also a common feature of allopatric hybrid zones, as early demonstrated by Meise (1928) for Corvus in Europe, and in some cases such variation is clearly associated with habitat features (Yang and Selander, 1968). The east-west asymmetry in width of the Mus zone corresponds to variation in steepness of environmental gradients, particularly precipitation (fig. 9), but also to elevation and, to some degree, soil type. Introgression of domesticus into musculus is relatively extensive in the west, where clinatic conditions similar to those of southern Jutland extend up the coast even to the north-western part of the peninsula beyond the Limfjord. This feature of variation argues that selection by environmental factors has some part in limiting introgression.

Theoretically, the observed east-west asymmetry in width could be caused by regional differences in rate of migration. For example, a greater density of farms supporting mouse populations might facilitate interfarm migration, thus producing a broader transition in genetic character. But we have no reason to suspect that migration rate is in fact higher in the west than in the east.

The lesser extent of introgression where extensive contact and hybridisation presumably have existed for the longest period is not the result of development of incipient reproductive isolating "mechanisms" (see theory of Dobzhansky, 1940, 1970), since, as noted earlier, we have no evidence of non-random mating or of sterility barriers in any part of the zone. It is also unlikely that earlier chance establishment of parental populations north and south of the present centre of the zone is responsible for the asymmetry, since the zone is narrowest where there has been the longest period of time available for colonisation.

In an attempt to identify particular environmental variables regulating introgression, we performed a step-wise multiple linear regression of hybrid index values for 17 sample areas near the mid-line of the zone against the following independent variables: altitude, total yearly precipitation, July precipitation, February precipitation, mean yearly temperature, mean July temperature, and mean February temperature (data from Danske Meteorol. Inst., 1933, representing averages for the period 1886-1925). The fraction $\left(R^{2}\right)$ of the sum of squares of $I$ attributable to the regression is only 0.50 , of which almost half $(0.23)$ is associated with July precipitation. Repeating the analysis with latitude as one of the independent variables, we obtained an $R^{2}$ of 0.88 , of which 0.77 results from the effect of latitude. Hence, considered apart from latitude, with which they are strongly correlated, precipitation, temperature, and altitude are not very useful " predictors" of the overall genetic character of populations in the hybrid zone. Either we have not identified all the important environmental variables or there are other factors influencing patterns of introgression.

\section{(iii) Differential introgression and selection}

If selection is a factor controlling the extent of introgression, it is, as Mayr (1963) has suggested, unlikely that it will affect all loci with the same intensity. Rather, it is to be expected that the progress of some alien alleles will 
be checked near the centre of the hybrid zone, while the flow of others will proceed varying distances into regions occupied by the parental populations.

Our analysis suggests that the geographic pattern of gene flow is distinctive for each locus. Variation is especially apparent among the three loci (Es-1, Es-2 and $I d h-1)$ at which alternate alleles are fixed or nearly so in the two semispecies. Idh- $1^{a}$ has penetrated into musculus populations beyond the Limfjord, whereas $E s-1^{b}$ can be detected only as far north as the southwestern edge of the Limfjord. Introgression of $M d h-2^{b}$ to regions north of the Limfjord is also suggested by the pattern of allele frequencies shown in fig. 7 .

Introgression of musculus alleles into domesticus is relatively limited but similarly variable. Idh- $1^{b}$ reaches the German border, and $E_{s-} 1^{a}$ goes further south than $E s-2^{c}$. There is a slight south-western introgression of $E_{s-5^{a}}$, but no apparent introgression of $M d h-2^{c}$.

Although linkage disequilibrium is difficult to assess in Mus populations because of their subdivided structure and the occurrence of null alleles at several of the loci, a comparison of allele frequencies at the linked loci $E_{s-1}$,

TABLE 1

Allele frequency correlations in central futland*

\begin{tabular}{|c|c|c|c|c|c|c|c|}
\hline & $E s-1^{b}$ & $E_{s-2^{b}}$ & $E s-3^{b}$ & $E s-5 a / a$ & $I d h-I^{a}$ & $M e-1^{a}$ & $M d h-2^{b}$ \\
\hline $\begin{array}{l}E s-1^{b} \\
E s-2^{b} \\
E s-3^{b} \\
E s-5^{a} / a^{a} \\
I d h-1^{a} \\
M e-1^{a} \\
M d h 2^{b}\end{array}$ & 1.00 & $\begin{array}{l}0.86 \\
1.00\end{array}$ & $\begin{array}{l}0.39 \\
0.51 \\
1.00\end{array}$ & $\begin{array}{r}-0.70 \\
-0.83 \\
-0.51 \\
1.00\end{array}$ & $\begin{array}{r}0.88 \\
0.84 \\
0.52 \\
-0.61 \\
1.00\end{array}$ & $\begin{array}{r}0.73 \\
0.84 \\
0.60 \\
-0.76 \\
0.81 \\
1.00\end{array}$ & $\begin{array}{r}0.36 \\
0.25 \\
-0.08 \\
-0.39 \\
0.21 \\
0.32 \\
1.00\end{array}$ \\
\hline
\end{tabular}

* 20 sample areas (7-11, 21-29, and 31-36).

$E s-2$ and $E s-5$ suggests that linkage between the loci studied is not an important factor affecting patterns of introgression. Shown in table 1 are correlations of allele frequencies between pairs of loci in the primary area in which introgression is occurring (bounded by dashed lines in fig. 7). There are

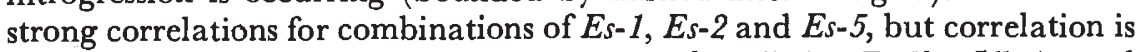
equally strong for the unlinked pairs $E s-1^{b}-I d h-1^{a}, E s-2^{b}-I d h-1^{a}$ and $E s-2^{b}-M e-1^{a}$. Near the centre of the hybrid zone individual farm populations are in equilibrium with regard to $E_{s-1} 1$ and $E_{s-5}$, and this is generally so also for $E s-1$ and $E s-2$ (table 2). But mild disequilibrium between the closely linked $E_{s-2}$ and $E_{s-5}$ loci is seen at about half the farms.

In the absence of relevant experimental data, our discussion of how selection operates in the hybrid zone is necessarily speculative. Following Ursin (1952), we conclude that the zone lies in a region where gradients of climatic factors, particularly precipitation, create environments to which the semispecies are equally well adapted. The east-west asymmetry in width of the zone reflects variation in extent of the area in which the critical set of intermediate environmental conditions is distributed. Direct selective pressures of the external environment may influence some aspects of allele frequency variation, but it is likely that selection resulting from the disruption of the respective co-adapted gene complexes of the parental forms is also involved. Particularly pertinent to the argument that the selective value of alleles at individual loci is determined in part by the internal genetic environment are 
the extreme steepness of the gradient of transition in genetic character and the fact that frequencies at all loci have a major shift along the same mid-point line. If the loci were simply responding to external environmental gradients, the mid-points of frequency would vary in position, although sigmoidal curves would result from the interaction of migration and selective gradients (Haldane, 1948; Fisher, 1950). Apparently selective coefficients for all alleles change sign along the Vejle-Grindsted-Skjern line. Our failure to find close relationships between geographic patterns of external environmental variables and introgressive patterns at individual loci also points to

TABLE 2

Genotypic combinations at paired loci in linkage group XVIII at farms in central futland

Farm: Observed (expected)

\begin{tabular}{|c|c|c|c|c|c|c|}
\hline \multirow{2}{*}{$\begin{array}{l}\text { Genotypic } \\
\text { combination }\end{array}$} & \\
\hline & $22 a$ & $23 a$ & $25 c$ & $27 b$ & $32 \mathrm{~b}$ & $32 c$ \\
\hline $\begin{array}{c}E_{s-1 / E_{s-2}} \\
\mathrm{aa} / \mathrm{bb} \\
\mathrm{aa} / \mathrm{cc} \\
\mathrm{aa} / \mathrm{bc} \\
\mathrm{bb} / \mathrm{bb} \\
\mathrm{bb} / \mathrm{cc} \\
\mathrm{bb} / \mathrm{bc} \\
\mathrm{ab} / \mathrm{bb} \\
\mathrm{ab} / \mathrm{cc} \\
\mathrm{ab} / \mathrm{bc} \\
\chi_{(\mathrm{d})}^{8}\end{array}$ & $\begin{array}{l}1(2) \\
3(3) \\
3(2) \\
8(5) \\
7(8) \\
2(5) \\
1(3) \\
6(5) \\
5(3) \\
7 \cdot 54\end{array}$ & $\begin{array}{c}1(1) \\
11(11) \\
17(18) \\
0(0) \\
0(0) \\
1(1) \\
0(0) \\
3(3) \\
5(5) \\
0.94\end{array}$ & $\begin{array}{r}0(0) \\
4(7) \\
11(8) \\
0(0) \\
3(2) \\
2(3) \\
0(0) \\
11(9) \\
8(10) \\
3 \cdot 67\end{array}$ & $\begin{array}{c}0(0) \\
14(14) \\
3(3) \\
0(0) \\
0(0) \\
0(0) \\
0(0) \\
6(6) \\
2(2) \\
0 \cdot 19\end{array}$ & $\begin{array}{c}8(7) \\
0(0) \\
0(1) \\
26(25) \\
0(0) \\
2(3) \\
25(27) \\
0(0) \\
5(3) \\
2 \cdot 41\end{array}$ & $\begin{array}{c}2(2) \\
20(16) \\
0(4) \\
0(0) \\
0(0) \\
0(0) \\
2(2) \\
6(10) \\
6(2) \\
12 \cdot 54^{*}\end{array}$ \\
\hline $\begin{array}{c}E_{s-1 / E_{s-5}} \\
\text { aa/aa } \\
\text { aa/b- } \\
\text { bb/aa } \\
\text { bb/b- } \\
\text { ab/aa } \\
\text { ab/b- } \\
\chi_{(\mathrm{s})}^{2}\end{array}$ & $\begin{aligned} & 6(6) \\
& 1(1) \\
& 16(16) \\
& 1(1) \\
& 11(11) \\
& 1(1) \\
& 0.42\end{aligned}$ & $\begin{array}{c}21(23) \\
8(6) \\
1(1) \\
0(0) \\
8(6) \\
0(2) \\
3 \cdot 16\end{array}$ & $\begin{aligned} & 14(14) \\
& 1(1) \\
& 5(5) \\
& 0(0) \\
& 18(18) \\
& 1(1) \\
& 0.37\end{aligned}$ & $\begin{array}{l}16(15) \\
1(2) \\
0(0) \\
0(0) \\
6(7) \\
2(1) \\
1 \cdot 71\end{array}$ & $\begin{array}{c}4(2) \\
4(6) \\
5(8) \\
23(20) \\
9(8) \\
21(22) \\
3 \cdot 39\end{array}$ & $\begin{aligned} & 17(15) \\
& 5(7) \\
& 0(0) \\
& 0(0) \\
& 7(9) \\
& 7(5) \\
& 2.78\end{aligned}$ \\
\hline $\begin{array}{c}E_{s-2 / E_{s-5}} \\
\mathrm{bb} / \mathrm{aa} \\
\mathrm{bb} / \mathrm{b}- \\
\mathrm{cc} / \mathrm{aa} \\
\mathrm{cc} / \mathrm{b}- \\
\mathrm{bc/aa} \\
\mathrm{bc/b}- \\
\chi_{(2)}^{8}\end{array}$ & $\begin{array}{c}9(9) \\
1(1) \\
14(15) \\
2(1) \\
10(9) \\
0(1) \\
1.33\end{array}$ & $\begin{array}{c}1(1) \\
0(0) \\
14(11) \\
0(3) \\
15(18) \\
8(5) \\
6.73^{*}\end{array}$ & $\begin{array}{c}0(0) \\
0(0) \\
18(17) \\
0(1) \\
19(20) \\
2(1) \\
1.73\end{array}$ & $\begin{array}{c}0(0) \\
0(0) \\
20(18) \\
0(2) \\
2(4) \\
3(1) \\
13.64^{* *}\end{array}$ & $\begin{array}{c}12(16) \\
47(43) \\
0(0) \\
0(0) \\
6(2) \\
1(5) \\
13.58^{* *}\end{array}$ & $\begin{aligned} & 1(3) \\
& 3(1) \\
& 20(17) \\
& 6(9) \\
& 3(4) \\
& 3(2) \\
& 5 \cdot 30\end{aligned}$ \\
\hline
\end{tabular}

the genetic environment as a factor determining the distribution of alleles. We are thus suggesting that recombination products of the parental musculus and domesticus genotypes are selected against by a combination of external and internal environmental factors. A similar argument was advanced by Clarke (1968) and Clarke and Murray (1971) to explain certain aspects of the distribution of colour-morph frequencies in Partula and Cepaea snails. And Carson (1972) has emphasised the fact that one-to-one correlations between genes and external environmental parameters are unlikely because " the object of selection is an interacting system rather than a single gene".

Disruption of the coadapted structure of the musculus gene pool may be causally related to the relatively widespread occurrence of minor $E s-2$ and 
$E s-3$ alleles in the northern part of the hybrid zone (figs. 4 and 5). Introgression from domesticus could modify the musculus pool in such a way that selective barriers to incorporation of new alleles are relaxed, or the minor alleles could even be favoured in low frequency in the "new" genetic environment created by introgression (see Stebbins, 1971).

Despite a long period of interbreeding not only in Jutland but also in Germany, the musculus and domesticus gene pools have not fused. Hence, our studies support the view that genetic isolation cannot be directly equated with reproductive isolation, since strongly integrated and co-adapted gene pools may be effectively protected against introgression even in the absence of reproductive isolation (Stebbins, 1950; Bigelow, 1965; Hagen and McPhail, 1970). Comparable cases have been analysed by Hagen (1967) in fishes and by Hall and Selander (1973) in lizards.

The behaviour of alleles at the structural loci examined in the present study does not seem readily compatible with the hypothesis that allozymic variants in populations and in closely allied species are selectively neutral (King and Jukes, 1969; Kimura and Ohta, 1971). However, the confirmed "neutralist" can point to the possibility that selection is affecting the chromosomal segments that the loci mark rather than the loci themselves. At present we see no way of resolving the problem of whether selection acts on the loci studied or on others with which they are very tightly linked. In any event, our study suggests that selection against potentially introgressive genes, presumably involving reduced fitness in backcross generations, is very strong, and that the degree of disruption of the coadapted parental gene complexes caused by introgression is not equal over all loci.

Acknowledgments.-H. M. Thamdrup and F. W. Braestrup provided laboratory facilities and assistance at the Zoological Institute of the University of Aarhus. Valuable assistance in the field or laboratory was also provided by C. Schrøder, A. Munk and A. M. Sørensen, and problems arising in connection with the work in Denmark were capably handled by $\mathrm{H}$. Walhovd, P. Valentin-Jensen, P. Bang and M. Lund. W. E. Johnson and S. Y. Yang provided helpful suggestions relating to electrophoresis, and C. S. Pankratz assisted in computer data processing. The contribution of $\mathrm{R}$. S. Ralin to preparation of the manuscript and figures is gratefully acknowledged.

This research was supported by NSF Grants GB-6662 and GB-15664 and NIH Grant GM-15769. Support from NIH Training Grants GM-00337 and MH-12476 is acknowledged by the senior author.

\section{REFERENCES}

ANDERSON, P. K., AND HILL, J. L. 1965. Mus musculus: experimental induction of territory formation. Science, $148,1753-1755$.

BERRY, R. J., AND MURPHY, H. M. 1970. The biochemical genetics of an island population of the house mouse. Proc. roy. Soc. B, 176, 87-103.

BIGELOW, R. s. 1965. Hybrid zones and reproductive isolation. Evolution, 19, 449-458.

BRUBAKER, L. L. 1970. A behavior-genetic study of race and deme differences in Mus musculus. Ph.D. thesis, University of Texas at Austin.

BRUNner, G. 1941. Die Kreuzgrotte bei Pottenstein (Ofr.) und das Peterloch bei Woppental (Opf.). Abh. Nat. Hist. Ges. Nürnberg, 27 (Fide Zimmermann, 1949).

CARson, H. L. 1972. Reorganization of the gene pool during speciation. Paper presented at Workshop on Population Structure, University of Hawaii, July, 1972.

CHAPMAN, V. M., RUDDLE, F. H., AND RODERICK, T. H. 1971. Linkage of isozyme loci in the mouse: phosphoglucomutase-2 (Pgm-2), mitochondrial NADP malate dehydrogenase (Mod-2), and dipeptidase-1 (Dip-1). Biochem. Genet., 5, 101-110.

CLARKE, B. 1968. Balanced polymorphism and regional differentiation in land snails. In Evolution and Environment, Ed. E. T. Drake, 351-368. Yale Univ. Press, New Haven. 
Clarke, B., AND Murray, J. 1971. Polymorphism in a Polynesian land snail Partula suturalis vexillum. In Ecological Genetics and Evolution, Ed. R. Creed, 51-64. Blackwell Scientific Publ., Oxford.

cook, L. M. 1972. Coefficients of Natural Selection. Hutchinson, London.

CROSBY, J. L. 1969. The evolution of genetic discontinuity: computer models of the selection of barriers to interbreeding between subspecies. Heredity, 25, 253-297.

DANSKE METEOROLOGISKE INSTITUT. 1933. Danmarks Klima. Copenhagen.

DAvies, E. (Ed.) 1944. Denmark: Geographic Handbook Series. [British] Naval Intelligence Division.

DEFRIES, J. C., AND MCCLEARN, G. E. 1972. Behavioral genetics and the fine structure of mouse populations: a study in microevolution. In Evolutionary Biology, Vol. 5, Ed. T. Dobzhansky, M. K. Hecht and W. C. Steere, 279-291. Appleton-Century-Crofts, New York.

DOBZHANSKY, T. 1940. Speciation as a stage in evolutionary divergence. Amer. Nat., 74, $312-321$.

Dobzhansky, T. 1970. Genetics of the Evolutionary Process. Columbia Univ. Press, New York.

FINCHAM, J. R. s. 1972. Heterozygous advantage as a likely general basis for enzyme polymorphisms. Heredity, 28, 387-391.

FISHER, R. A. 1950. Gene frequencies in a cline determined by selection and diffusion. Biometrics, 6, 353-361.

FORD, E. B. 1971. Ecological Genetics, Third Ed. Chapman and Hall, London.

HAGEN, D. W. 1967. Isolating mechanisms in threespine sticklebacks (Gasterosteus). $\mathcal{F}$. Fish. Res. Bd. Canada, 24, 1637-1692.

HAGEN, D. W., AND MCPHAIL, J. D. 1970. The species problem within Gasterosteus aculeatus on the Pacific Coast of North America. F. Fish. Res. Bd. Canada, 27, 147-155.

haldane, J. B. s. 1948. The theory of a cline. J. Genet., 48, 277-284.

HALL, W. P., AND SELANDER, R. K. 1973. Hybridization in karyotypically differentiated populations of the Sceloporus grammicus complex (Iguanidae). Evolution, 27, in press.

HENDERSON, N. s. 1966. Isozymes and genetic control of NADP-malate dehydrogenase in mice. Arch. Biochem. Biophys., 117, 28-33.

HUNT, w. G. 1970. Biochemical variation in hybridizing subspecies of the house mouse (Mus musculus) in Europe. Ph.D. thesis, University of Texas at Austin.

HUTTON, J. J., AND RODERICK, T. H. 1970. Linkage analyses using biochemical variants in mice. III. Linkage relationships of eleven biochemical markers. Biochem. Genet., 4, 339-350.

HUXLEY, J. 1943. Evolution: The Modern Synthesis. Harper, New York.

JAIN, S. K., AND BRADSHAW, A. D. 1966. Evolutionary divergence among adjacent plant populations. I. The evidence and its theoretical analysis. Heredity, 21, 407-441.

KImURA, M., AND oHta, T. 1971. Theoretical Aspects of Population Genetics. Princeton Univ. Press, Princeton.

KING, J. L., AND JUKES, T. H. 1969. Non-Darwinian evolution. Science, 164, 788-798.

MAYR, E. 1963. Animal Species and Evolution. Harvard Univ. Press, Cambridge.

MEISE, w. 1928. Die Verbreitung der Aaskrähe (Formenkreis Corous corone L.). J.f. Ornithol., 76, 1-203.

PETras, M. L., AND BIDDLE, F. G. 1967. Serum esterases in the house mouse, Mus musculus. Canad. 7. Genet. Cytol., 9, 704-710.

PETRAs, M. L., ReIMer, J. D., BIDDLE, F. G., MARTIN, J. E., AND linton, R, s. 1969. Studies of natural populations of Mus. V. A survey of nine loci for polymorphisms. Canad. $\mathcal{F}$. Genet. Cytol., 11, 497-513.

POPP, R. A. 1967. Linkage of $E s-1$ and $E s-2$ in the mouse. F. Hered., 58, 186-188.

REIMER, J. D., AND PETRAs, M. L. 1967. Breeding structure of the house mouse, Mus musculus, in a population cage. J. Mammal., 48, 88-99.

REMINGTON, C. L. 1968. Suture-zones of hybrid interaction between recently joined biotas. In Evolutionary Biology, Vol. 2, Ed. T. Dobzhansky, M. K. Hecht and W. C. Steere, 321-428. Appleton-Century-Crofts, New York.

RODERICK, T. H., HUTTON, J. J., AND RUDDLE, F. H. 1970. Linkage of esterase-3 (Es-3) and Rex $(R e)$ on linkage group VII of the mouse. J. Hered., 61, 278-279.

RODERICK, T. H., RUDDLE, F. H., CHAPMAN, V. M., AND shows, T. B. 1971. Biochemical polymorphisms in feral and inbred mice (Mus musculus). Biochem. Genet., 5, 457-466.

RUDDLE, F. H., RODERICK, T. H., SHOWS, T. B., WEIGL, P. G., CHIPMAN, R. K., AND ANDERSON, P. K. 1969. Measurements of genetic heterozygosity by means of enzyme polymorphisms in wild populations of the mouse. $\mathcal{F}$. Hered., $60,321-322$. 
RUDDLE, F. H., SHOWs, T. B., AND RODERIGK, T. H. 1969. Esterase genetics in Mus musculus: expression, linkage and polymorphism of locus $E_{s-2}$. Genetics, 62, 393-399.

SCHWARz, E., AND SGHWARz, H. K. 1943. The wild and commensal stocks of the house mouse, Mus musculus Linnaeus. 7. Mammal., 24, 59-72.

SELANDER, R. K. 1970 . Behavior and genetic variation in natural populations. Amer. Zool., 10, 53-66.

SELANDER, R. K., AND JOHNson, w. E. 1973. Genetic variation among vertebrate species. Ann. Rev. Ecol. Syst., 4, in press.

SELANDER, R. K., AND YANG, s. Y. 1969. Protein polymorphism and genic heterozygosity in a wild population of the house mouse (Mus musculus). Genetics, 63, 653-667.

SELANDER, R. K., HUNT, w. G., AND YaNG, s. Y. 1969. Protein polymorphism and genic heterozygosity in two European subspecies of the house mouse. Evolution, 23, 379-390.

SELANDER, R. K., YANG, S. Y., AND HUNT, W. G. 1969. Polymorphism in esterases and hemoglobin in wild populations of the house mouse (Mus musculus). Studies in Genetics V, Univ. Texas Publ. 6918, 271-338.

sHORT, L. L., JR. 1965. Hybridization in the flickers (Colaptes) of North America. Bull. Amer. Mus. Nat. Hist., 129, 307-428.

sHows, T. B., CHAPMAN, v. M., AND RUDDLE, F. н. 1970. Mitochondrial malate dehydrogenase and malic enzyme: Mendelian inherited electrophoretic variants in the mouse. Biochem. Genet., 4, 707-718.

stebbins, G. L. 1950. Variation and Evolution in Plants. Columbia Univ. Press, New York.

stebrins, G. L. 1971. Processes of Organic Evolution, Second Ed. Prentice-Hall, Englewood Cliffs, N.J.

TAYLOR, B. A. 1972. Genetic relationships between inbred strains of mice. 7. Hered., 63, 83-86.

URsIN, E. 1952. Occurrence of voles, mice, and rats (Muridae) in Denmark, with a special note on a zone of intergradation between two subspecies of the house mouse (Mus musculus L.). Vid. Medd. Dansk Naturhist. Foren., 114, 217-244.

WAterbolk, н. T. 1968. Food production in prehistoric Europe. Science, 162, 1093-1102.

WHEELER, L. L. 1972. Inheritance of allozymes in subspecific $F_{1}$ hybrids of Mus musculus from Denmark. Studies in Genetics VII, Univ. Texas Publ. 7213, 319-326.

WHEELER, L. L., AND SELANDER, R. K. 1972. Genetic variation in populations of the house mouse, Mus musculus, in the Hawaiian Islands. Studies in Genetics VII, Univ. Texas Publ. 7213, 269-296.

wirson, E. o. 1965. The challenge from related species. In The Genetics of Colonizing Species, Ed. H. G. Baker and G. L. Stebbins, 7-27. Academic Press, New York.

YANG, S. Y., AND SELANDER, R. K. 1968. Hybridization in the grackle Quiscalus quisculas in Louisiana. Syst. Zool., 17, 107-143.

zimmermanN, K. 1949. Zur Kenntnis der mitteleuropäischen Hausmäuse. Zool. Jahrb. (Syst.), 78, 301-322. 